\title{
Early combined treatment with sildenafil and adipose-derived mesenchymal stem cells preserves heart function in rat dilated cardiomyopathy
}

Yu-Chun Lin ${ }^{1,2+}$, Steve Leu ${ }^{1,2}$, Cheuk-Kwan Sun ${ }^{3+}$, Chia-Hung Yen ${ }^{4}$, Ying-Hsien Kao ${ }^{5}$, Li-Teh Chang ${ }^{6}$, Tzu-Hsien Tsai ${ }^{1}$, Sarah Chua ${ }^{1}$, Morgan Fu', Sheung-Fat Ko ${ }^{7}$, Chiung-Jen Wu', Fan-Yen Lee ${ }^{8+}$, Hon-Kan Yip ${ }^{1,2^{*}}$

\begin{abstract}
Background: We investigated whether early combined autologous adipose-derived mesenchymal stem cell (ADMSC) and sildenafil therapy offers an additive benefit in preserving heart function in rat dilated cardiomyopathy (DCM).

Methods: Adult Lewis rats ( $\mathrm{n}=8$ per group) were divided into group 1 (normal control), group 2 (saline-treated DCM rats), group $3\left[2.0 \times 10^{6}\right.$ ADMSC implanted into left ventricular (LV) myocardium of DCM rats], group 4 (DCM rats with sildenafil $30 \mathrm{mg} / \mathrm{kg} / \mathrm{day}$, orally), and group 5 (DCM rats with combined ADMSC-sildenafil). Treatment was started 1 week after DCM induction and the rats were sacrificed on day 90.

Results: The results showed that mitochondrial protein expressions of connexin 43 and cytochrome- $C$ were lowest in group 2, and lower in groups 3 and 4 than in group $5(p<0.002)$. Conversely, oxidative index was highest in group 2, and also higher in groups 3 and 4 than in group $5(p<0.0003)$. The mRNA expressions of interleukin (IL)10, Gro/LL-8, endothelial nitric oxide synthase, and BCl-2 were lowest in group 2, and lower in groups 3 and 4 compared with group 5 ( $p<0.0001)$. The mRNA expressions of matrix metalloproteinase-9, Bax, caspase 3 , and stromal-cell derived factor- $1 \alpha$ were highest in group 2, and higher in groups 3 and 4 than in group $5(p<0.0004)$. Apoptosis and fibrosis in LV myocardium were most prominent in group 2 and higher in groups 3 and 4 than in group 5, whereas angiogenesis and LV ejection fraction were lowest in group 2 and lower in groups 3 and 4 than in group $5(p<0.003)$.
\end{abstract}

Conclusion: Early combined ADMSC/sildenafil is superior to either treatment alone in preserving LV function.

\section{Background}

Different treatment strategies for patients with symptomatic dilated cardiomyopathy (DCM) have been extensively investigated [1-5]. Although medications including angiotensin converting enzyme inhibitors/angiotensin II type I blockers, and beta-blockers have been recognized as some of the most effective therapeutic regimes in improving left ventricular (LV) function, congestive

\footnotetext{
* Correspondence: han.gung@msa.hinet.net

† Contributed equally

'Division of cardiology, Department of Internal Medicine, Chang Gung Memorial Hospital-Kaohsiung Medical Center, Chang Gung University

College of Medicine, Kaohsiung, Taiwan

Full list of author information is available at the end of the article
}

heart failure (CHF), and long-term outcome for patients with DCM $[1-3,6,7]$, the mortality rate of this patient population remains high. A safe and more effective therapeutic option for improving LV function and the longterm outcome of DCM patients is urgently needed.

Growing data demonstrate that cell therapy can improve cardiac function both in the rat model of acute myocardial infarction (AMI) and in patients with ischemic cardiomyopathy or following AMI [8-12]. Cell therapy, therefore, has been suggested to be a promising novel therapeutic strategy for restoration of heart function in the settings of ischemic cardiomyopathy or AMI [8-13]. However, the potential impact of cell therapy on 
DCM in attenuating LV remodeling and preserving LV function has not been fully investigated [13]. Additionally, before envisaging cell-based therapy for improving ischemia-related myocardial dysfunction, some unresolved issues still need to be clarified: 1) the ideal cell source for transplantation, 2) the most appropriate route of cell administration, and, 3) the best approach to achieve an optimal cellular uptake by the recipient organ, thereby attaining a functional integration of the transplanted cells and the host tissue.

As compared with embryonic stems cells and bone marrow-derived mesenchymal stem cells, adiposederived mesenchymal stem cells (ADMSCs) have the distinct advantages of being abundant, easy to obtain with minimal invasiveness, and readily cultured to a sufficient number for autologous transplantation without ethical issue. Previous study has also demonstrated a therapeutic superiority of ADMSCs over bone marrowderived mesenchymal stem cells in an animal model of liver injury [14]. It is, therefore, conceivable that ADMSCs would be of tremendous momentum in translational medicine for potential clinical application in patients with cardiovascular ischemic syndrome in the near future.

Sildenafil, a phosphodiesterase type-5 (PDE-5) inhibitor, has been widely utilized in the management of erectile dysfunction in men [15,16]. Consistently, experimental studies have identified abundant distribution of PDE-5 in vascular smooth muscle cells [17] that has been demonstrated to cause vasodilatation through an increase of cyclic guanosine 3', 5'-monophospahte (cGMP) concentration $[18,19]$. In addition, a small clinical trial has recently reported an improvement in the symptoms of CHF in patients with DCM [20].

Although our recent study has shown that implantation of bone marrow-derived MSCs can effectively preserve cardiac function in an animal model of DCM, LV dysfunction and remodeling were actually partially rather than completely reversed by this treatment strategy [13]. Importantly, based on the experience from our clinical practice, early management is always better than a delayed treatment at all stages of development of the disease. Accordingly, the experimental protocol was designed to focus on the treatment of early stages of DCM during disease initiation rather than treatment of the established condition. The purposes of this study were to test the hypothesis that early combined treatment with autologous ADMSC implantation into LV myocardium and oral sildenafil is superior to either autologous ADMSC transplantation or sildenafil alone in the preservation of LV function in early DCM as well as to elucidate the underlying mechanisms of biologic signaling. The model used in this study is based on the development of cardiomyopathy from autoimmune myositis elicited through the administration of porcine heart myosin plus Freund complete adjuvant which is known to induce selective DCM in male Lewis rats [21].

\section{Methods}

\section{Ethics}

All experimental animal procedures were approved by the Institute of Animal Care and Use Committee at our hospital and performed in accordance with the Guide for the Care and Use of Laboratory Animals (NIH publication No. 85-23, National Academy Press, Washington, DC, USA, revised 1996).

\section{Animal Model of DCM}

Experimental procedures were performed in pathogenfree, adult male Lewis rats weighing 275-300 g (Charles River Technology, BioLASCO Taiwan Co., Ltd., Taiwan). The rats were initially randomized into five groups before isolation of ADMSCs. DCM was induced via experimental myocarditis based on previous studies [21] and our recent reports [13]. Briefly, $1 \mathrm{mg}(0.1 \mathrm{~mL})$ of porcine heart myosin (Sigma) was mixed with an equal volume of Freund complete adjuvant (Sigma) and injected into the footpad of each animal on day 1 and day 7. Five weeks after immunization, these rats served as models for heart failure due to DCM $[13,21]$.

\section{Isolation of Adipose-Derived Mesenchymal Stem Cells from Rat}

The 20 rats in groups 3 and 5 were anesthetized with inhalational isoflurane on day 7 prior to DCM induction. Adipose tissue surrounding the epididymis was carefully dissected and excised. Then 200-300 $\mu \mathrm{L}$ of sterile saline was added to every $0.5 \mathrm{~g}$ of tissue to prevent dehydration. The tissue was cut into $<1 \mathrm{~mm}^{3}$ size pieces using a pair of sharp, sterile surgical scissors. Sterile saline $\left(37^{\circ} \mathrm{C}\right)$ was added to the homogenized adipose tissue in a ratio of 3:1 (saline: adipose tissue), followed by the addition of stock collagenase solution to a final concentration of 0.5 units $/ \mathrm{mL}$. The centrifuge tubes with the contents were placed and secured on a Thermaline shaker and incubated with constant agitation for $60 \pm 15 \mathrm{~min}$ at $37^{\circ} \mathrm{C}$. After 40 minutes of incubation, the content was triturated with a $25 \mathrm{~mL}$ pipette for 2-3 min. The cells obtained were placed back to the rocker for incubation. The contents of the flask were transferred to $50 \mathrm{~mL}$ tubes after digestion, followed by centrifugation at $600 \mathrm{~g}$, for 5 minutes at room temperature. The fat layer and saline supernatant from the tube were poured out gently in one smooth motion or removed using vacuum suction. The cell pellet thus obtained was resuspended in $40 \mathrm{~mL}$ saline and then centrifuged again at $600 \mathrm{~g}$ for 5 minutes at room temperature. After being resuspended again in $5 \mathrm{~mL}$ saline, 
the cell suspension was filtered through a $100 \mathrm{~mm}$ filter into a $50 \mathrm{~mL}$ conical tube to which $2 \mathrm{~mL}$ of saline was added to rinse the remaining cells through the filter. The flow-through was pipetted into a new $50 \mathrm{~mL}$ conical tube through a $40 \mathrm{~mm}$ filter. The tubes were centrifuged for a third time at $600 \mathrm{~g}$ for 5 minutes at room temperature. The cells were resuspended in saline. An aliquot of cell suspension was then removed for cell culture in DMEM-low glucose medium containing 10\% FBS for two weeks. Approximately $2.0 \times 10^{6}$ ADMSCs were obtained from each rat. Flow cytometric analysis was performed for identification of cellular characteristics after cell-labeling with appropriate antibodies 30 minutes before transplantation (Table 1).

\section{Randomization}

Eight healthy Lewis rats served as sham controls (group 1) in this study. DCM was induced in 32 Lewis rats, including those 20 rats of ADMSC isolation which were then randomized into group 2 (saline-treated DCM), group $3\left(2.0 \times 10^{6}\right.$ ADMSC implanted into LV anterior wall), group 4 (sildenafil $30 \mathrm{mg} / \mathrm{kg} /$ day, orally), and group 5 (combined sildenafil and ADMSC). ADMSC transplantation and oral sildenafil were given on day 7 after DCM induction, while all the animals were sacrificed on day 90 .

\section{Rationale of Sildenafil Dosage and Early Combined Therapy}

The dosage of sildenafil in this study was according to our recent report [22]. In addition, the choice of a relatively early timing of treatment was based on our aim of evaluating the therapeutic effect of the combined regimen on early DCM.

\begin{tabular}{|c|c|c|c|}
\hline ADMSC surface markers & Day $0(n=6)$ & Day $14(n=6)$ & p value* \\
\hline CD31+ & $23.1 \pm 6.3$ & $43.1 \pm 15.3$ & 0.067 \\
\hline KDR+ & $18.0 \pm 9.8$ & $44.6 \pm 14.7$ & 0.040 \\
\hline CD45+ & $20.4 \pm 10.5$ & $44.6 \pm 14.5$ & 0.034 \\
\hline CD27+ & $13.5 \pm 2.8$ & $42.5 \pm 16.5$ & 0.009 \\
\hline VEGF+ & $15.3 \pm 8.3$ & $41.6 \pm 17.8$ & 0.045 \\
\hline VWF+ & $14.7 \pm 8.3$ & $43.7 \pm 18.1$ & 0.021 \\
\hline c-Kit+ & $8.8 \pm 5.1$ & $11.8 \pm 7.9$ & 0.443 \\
\hline Sca-1+ & $1.4 \pm 1.1$ & $0.7 \pm 0.5$ & 0.283 \\
\hline CD29+ & $33.8 \pm 22.7$ & $64.6 \pm 19.1$ & 0.013 \\
\hline CD34+ & $18.6 \pm 7.3$ & $4.5 \pm 3.7$ & 0.006 \\
\hline CD90+ & $42.3 \pm 12.2$ & $54.8 \pm 22.0$ & 0.257 \\
\hline Troponin-I+ & $15.4 \pm 5.6$ & $20.6 \pm 15.4$ & 0.551 \\
\hline
\end{tabular}

*By paired-T test.

ADMSC $=$ adipose-derived mesenchymal stem cell; VEGF $=$ vascular endothelial cell growth factor; $\mathrm{VWF}=$ von Willebrand factor.

\section{ADMSC Labeling and Implantation}

On day 14, CM-Dil (Vybrant ${ }^{\text {ma }}$ Dil cell-labeling solution, Molecular Probes, Inc.) $(50 \mu \mathrm{g} / \mathrm{ml})$ was added to the culture medium 30 minutes before implantation of ADMSCs. After completion of ADMSC labeling, all animals were anesthetized by chloral hydrate $(35 \mathrm{mg} / \mathrm{kg}$ i. p.) and placed in a supine position on a warming pad at $37^{\circ} \mathrm{C}$, followed by endotracheal intubation with positivepressure ventilation $(180 \mathrm{~mL} / \mathrm{min})$ with room air using a Small Animal Ventilator (SAR-830/A, CWE, Inc., USA). Under sterile conditions, the heart was exposed via a left thoracotomy. Using a 30 -gauge needle, approximately $2 \times 10^{6}$ ADMSCs in $100 \mu$ l culture medium IMDM were implanted in myocardium of LV anterior wall over six different sites in groups 3 and 5, while group 2 rats received $100 \mu \mathrm{l}$ saline over the same regions of LV. Groups 1 and 4 animals received thoracotomy only without cardiac injection. After the procedures, all animals were allowed to remain on the warming pad and recover under care.

\section{Functional Assessment by Echocardiography}

Transthoracic echocardiography was performed in each group prior to and on day 35 and day 90 after DCM induction with the anesthetized rats in a supine position by an animal cardiologist blinded to the design of the experiment using a commercially available echocardiographic system (UF-750XT) equipped with a 8-MHz linear-array transducer for animals (FUKUDA Denshi Co. Hongo, Bunkyo-Ku, Tokyo, Japan). M-mode tracings of LV were obtained with the heart being imaged in 2dimensional mode in short-axis at the level of the papillary muscle. Left ventricular internal dimensions [endsystolic diameter (ESD) and end-diastolic diameter (EDD)] were measured according to the American Society of Echocardiography leading-edge method using at least three consecutives cardiac cycles. The LV ejection fraction (LVEF) was calculated as follows:

$$
\operatorname{LVEF}(\%)=\left[\left(\operatorname{LVEDD}^{3}-\operatorname{LVEDS}^{3}\right) / \operatorname{LVEDD}^{3}\right] \times 100
$$

\section{Histological and Immunohistochemical Studies}

Engraftment of troponin I-positive, CD31-positive, and $\alpha$-smooth muscle actin ( $\alpha$-SMA)-positive ADMSCs was assessed by examining the implanted areas after immunohistochemical labeling using respective primary antibodies based on our recent study [13]. Irrelevant antibodies were used as controls.

\section{TUNEL Assay for Apoptotic Nuclei}

For each rat, 6 sections (3 longitudinal and 3 transverse sections of LV myocardium) were analyzed by an in situ Cell Death Detection Kit, AP (Roche) according to the 
manufacturer's guidelines. The TUNEL-positive cells were examined in 3 randomly chosen high-power fields (HPFs) $(\times 400)$. The mean number per HPF for each animal was then determined by summation of all numbers divided by 18 .

\section{Integrated Area of CD31-Positively stained cells}

The integrated area $\left(\mu \mathrm{m}^{2}\right)$ of CD31+ spot area in the tissue sections was calculated using Image Tool 3 (IT3) image analysis software (University of Texas, Health Science Center, San Antonio, UTHSCSA; Image Tool for Windows, Version 3.0, USA) as described previously [13]. Three selected sections were quantified for each animal. Three randomly selected HPFs $(400 \times)$ were analyzed in each section. After determining the number of pixels in each CD31+ spot area per HPF, the numbers of pixels obtained from the three HPFs were summated. The procedure was repeated in two other sections for each animal. The mean pixel number per HPF for each animal was then determined by summating all pixel numbers and dividing by 9 . The mean area of CD31+ spot area per HPF was obtained using a conversion factor of 19.24. (1 $\mu \mathrm{m}^{2}$ represented 19.24 pixels).

\section{Histological Study of Fibrosis Area}

Masson's trichrome staining was used for studying fibrosis of LV myocardium. The method of calculating the integrated area $\left(\mu \mathrm{m}^{2}\right)$ of fibrosis in LV myocardium in the tissue sections was identical to that for the integrated area $\left(\mu \mathrm{m}^{2}\right)$ of CD31+ spot area using Image Tool 3 (IT3) image analysis software.

\section{Western Blot Analysis for Connexin (Cx)43, Cytochrome-C in Mitochondria and Oxidative Stress Reaction in LV Myocardium}

Equal amounts (10-30 mg) of protein extracts from remote viable LV myocardium were loaded and separated by SDS-PAGE using $8-10 \%$ acrylamide gradients. Following electrophoresis, the separated proteins were transferred electrophoretically to a polyvinylidene difluoride (PVDF) membrane (Amersham Biosciences). Nonspecific proteins were blocked by incubating the membrane in blocking buffer (5\% nonfat dry milk in TTBS containing $0.05 \%$ Tween 20 ) overnight. The membranes were incubated with the indicated primary antibodies (Cx43, 1:1000, Chemicon; Cytochrome C, 1:1000, BD Biosciences; Actin, 1:10000, Chemicon) for $1 \mathrm{~h}$ at room temperature. Horseradish peroxidase-conjugated anti-mouse immunoglobulin IgG (1:2000, Amersham Biosciences) was applied as the second antibody for $1 \mathrm{~h}$ at room temperature. The washing procedure was repeated eight times within $1 \mathrm{~h}$. The Oxyblot Oxidized Protein Detection Kit was purchased from Chemicon (S7150). The oxyblot procedure was performed according to a previous study [13,22]. The procedure of 2,4-dinitrophenylhydrazine (DNPH) derivatization was carried out on $6 \mu \mathrm{g}$ of protein for 15 minutes according to manufacturer's instructions. One-dimensional electrophoresis was carried out on 12\% SDS/polyacrylamide gel after DNPH derivatization. Proteins were transferred to nitrocellulose membranes which were then incubated in the primary antibody solution (anti-DNP 1: 150) for $2 \mathrm{~h}$, followed by incubation with second antibody solution (1:300) for $1 \mathrm{~h}$ at room temperature. The washing procedure was repeated eight times within 40 minutes. Immunoreactive bands were visualized by enhanced chemiluminescence (ECL; Amersham Biosciences) which was then exposed to Biomax L film (Kodak). For quantification, ECL signals were digitized using Labwork software (UVP). For oxyblot protein analysis, a standard control was loaded on each gel.

\section{Vessel Density in LV Myocardium}

Immunohistochemical staining of blood vessels was performed with $\alpha$-SMA (1:400) as primary antibody at room temperature for $1 \mathrm{~h}$, followed by washing with PBS thrice. Ten minutes after the addition of the antimouse-HRP conjugated secondary antibody, the tissue sections were washed with PBS thrice. The 3,3' diaminobenzidine (DAB) $(0.7 \mathrm{gm} /$ tablet) (Sigma) was then added, followed by washing with PBS thrice after one minute. Finally, hematoxylin was added as a counterstain for nuclei, followed by washing twice with PBS after one minute. Three sections of LV myocardium were analyzed in each rat. For quantification, three randomly selected HPFs $(\times 100)$ were analyzed in each section. The mean number per HPF for each animal was then determined by summation of all numbers divided by 9 .

\section{Real-Time Quantitative PCR Analysis}

Real-time polymerase chain reaction (RT-PCR) was conducted using LightCycler TaqMan Master (Roche, Germany) in a single capillary tube according to the manufacturer's guidelines for individual component concentrations. Forward and reverse primers were each designed based on individual exon of the target gene sequence to avoid amplifying genomic DNA.

During PCR, the probe was hybridized to its complementary single-strand DNA sequence within the PCR target. As amplification occurred, the probe was degraded due to the exonuclease activity of Taq DNA polymerase, thereby separating the quencher from reporter dye during extension. During the entire amplification cycle, light emission increased exponentially. A positive result was determined by identifying the threshold cycle value at which reporter dye emission appeared above background. 


\section{Statistical Analysis}

Data were expressed as mean values (mean \pm SD). Statistical analysis was adequately performed by unpaired Student $t$ test or analysis of variance, followed by Tukey multiple comparison procedure. SAS statistical software for Windows version 8.2 was utilized (SAS institute, Cary, NC). A probability value $<0.05$ was considered statistically significant.

\section{Results}

\section{Group Mortality Rates}

No mortality was noted in group 1 (sham control) within the study period. However, two rats died in groups 2 to 5 during the procedure or less than 3 days after the procedure. Fischer exact test revealed no significant difference in mortality rates among the five groups $(\mathrm{p}=0.666)$.

\section{Flow Cytometry Findings of Cultured ADMSC Surface Markers}

Flow cytometric analysis demonstrated that cellular expressions of the surface makers for endothelial progenitor cells (EPC) (C-kit, Sca-1) were relatively low prior to cell culture and did not significantly change after 14-day culture (Table 1). Additionally, the percentage of cells positively stained for troponin, an index of myogenic-like cell marker, was also relatively low prior to cell culture and did not significantly change after 14day culture. However, surface makers for EPCs (CD31, CD34, KDR,) and endothelial cell (VEGF, vWF) were remarkably increased after 14-day culture. Furthermore, the expressions of surface markers of mesenchymal stem cell (CD27, CD29, CD45 and CD90) were remarkably higher following 14 days of culturing.

\section{Body Weight, Heart Weight, Lung Weight, and Serial Echocardiographic Findings}

The initial and final body weight did not differ among the five groups, whereas the final heart weight and left lung weight were significantly higher in group 2 (i.e.
DCM only) than in other groups (Table 2). There was also no significant difference in initial LVEF among all groups. Additionally, the femoral arterial blood pressure did not differ among five groups on day 90 following DCM induction. However, on day 35 and day 90 following DCM induction, the LVEF was significantly reduced in group 2 compared with that in other groups, and notably lower in groups 3 (ADMSC therapy) and 4 (sildenafil therapy) than in groups 1 (normal control) and 5 (combined ADMSC and sildenafil therapy) but it did not differ between groups 1 and 5 (Table 2).

\section{Identification of Implanted ADMSCs and CD31+ Cells in LV Myocardium}

By day 90 following DCM induction, the rats were sacrificed for identifying implanted ADMSCs in LV myocardium. Numerous CM-Dil-stained undifferentiated ADMSCs were found to have engrafted (Figure 1B and 1E). However, only some implanted CM-Dil-stained cells presenting as myogenic-like cells were stained positively for troponin I (Figure $1 \mathrm{C}$ and $1 \mathrm{~F}$ ). In contrast, numerous CD31+ stained spots were identified in group 3 (Figure $1 \mathrm{I}$ ), and significantly higher spot area (Figure $1 \mathrm{~L}$ ) was noted in group 5 as compared with group 3 in LV myocardium on day 90 after DCM induction (Figure 1M).

\section{Apoptosis in LV Myocardium}

The number of apoptotic nuclei was similar between groups 3 and 4 (Figure 2A-F). However, the number of apoptotic nuclei was substantially higher in group 2 than in other groups, remarkably higher in groups 3 and 4 than in groups 1 and 5 , and it was also notably higher in group 5 than in group 1.

\section{Fibrosis of LV Myocardium}

Mean area of fibrotic tissue did not differ between groups 3 and 4 on Masson's trichrome staining (Figure 2G-L). However, the mean area of fibrotic tissue was substantially higher in group 2 than in other groups, remarkably higher

Table 2 Summarized Body Weight, Heart Weight, Left Lung Weight and Heart Function in Studied Animals

\begin{tabular}{|c|c|c|c|c|c|c|}
\hline Variables & Group 1t $(n=8)$ & Group $2 \dagger(n=8)$ & Group $3+(n=8)$ & Group $4 \dagger(n=8)$ & Group $5 \dagger(n=8)$ & p value* \\
\hline Initial body weight (g) & $328 \pm 15.9$ & $323 \pm 11.8$ & $323 \pm 12.6$ & $317 \pm 24.3$ & $325 \pm 25.8$ & 0.792 \\
\hline Final body weight (g) & $450.0 \pm 35.7$ & $468.9 \pm 26.4$ & $476.5 \pm 25.9$ & $446.0 \pm 29.9$ & $465.7 \pm 59.0$ & 0.498 \\
\hline Final left lung weight (g) & $1.70^{a} \pm 0.09$ & $2.01^{b} \pm 0.15$ & $1.76^{a} \pm 0.16$ & $1.78^{\mathrm{a}} \pm 0 . .21$ & $1.78^{a} \pm 0.08$ & 0.0009 \\
\hline Final heart weight $(\mathrm{g})$ & $1.46^{\mathrm{a}} \pm 0.11$ & $1.80^{b} \pm 0.24$ & $1.55^{\mathrm{a}, \mathrm{b}} \pm 0.24$ & $1.51^{\mathrm{a}, \mathrm{b}} \pm 0.28$ & $1.42^{\mathrm{a}} \pm 0.26$ & 0.023 \\
\hline Day 0 LVEF (\%) & $79.3 \pm 2.0$ & $79.3 \pm 3.5$ & $80.9 \pm 2.3$ & $79.3 \pm 3.2$ & $80.9 \pm 4.7$ & 0.744 \\
\hline Day-30 LVEF (\%) & $79.8^{a} \pm 2.5$ & $72.1^{b} \pm 1.7$ & $74.8^{a, b} \pm 3.2$ & $75.9^{a, b} \pm 5.0$ & $78.7^{\mathrm{a}} \pm 4.0$ & 0.0005 \\
\hline Day-90 LVEF (\%) & $79.1^{a} \pm 3.3$ & $70.2^{b} \pm 2.3$ & $74.3^{a, b} \pm 0.6$ & $74.5^{\mathrm{a}, \mathrm{b}} \pm 3.8$ & $78.6^{a, b} \pm 3.0$ & $<0.0001$ \\
\hline FASBP on day $90, \mathrm{mmHg}$ & $122 \pm 26$ & $116 \pm 21$ & $109 \pm 19$ & $103 \pm 22$ & $108 \pm 21$ & 0.213 \\
\hline
\end{tabular}

*: by one-way ANOVA. Different superscript letters between the groups indicate significant difference (at 0.05 level) by Tukey's multiple comparison procedure. t: Group 1 = normal control; Group 2 = DCM only; Group 3 = DCM plus ADMSC; Group 4 = DCM plus sildenafil; Group $5=$ DCM plus combined sildenafil and ADMSC.

$\mathrm{FABP}=$ femoral arterial blood pressure; $\mathrm{LVEF}=$ left ventricular ejection fraction. 


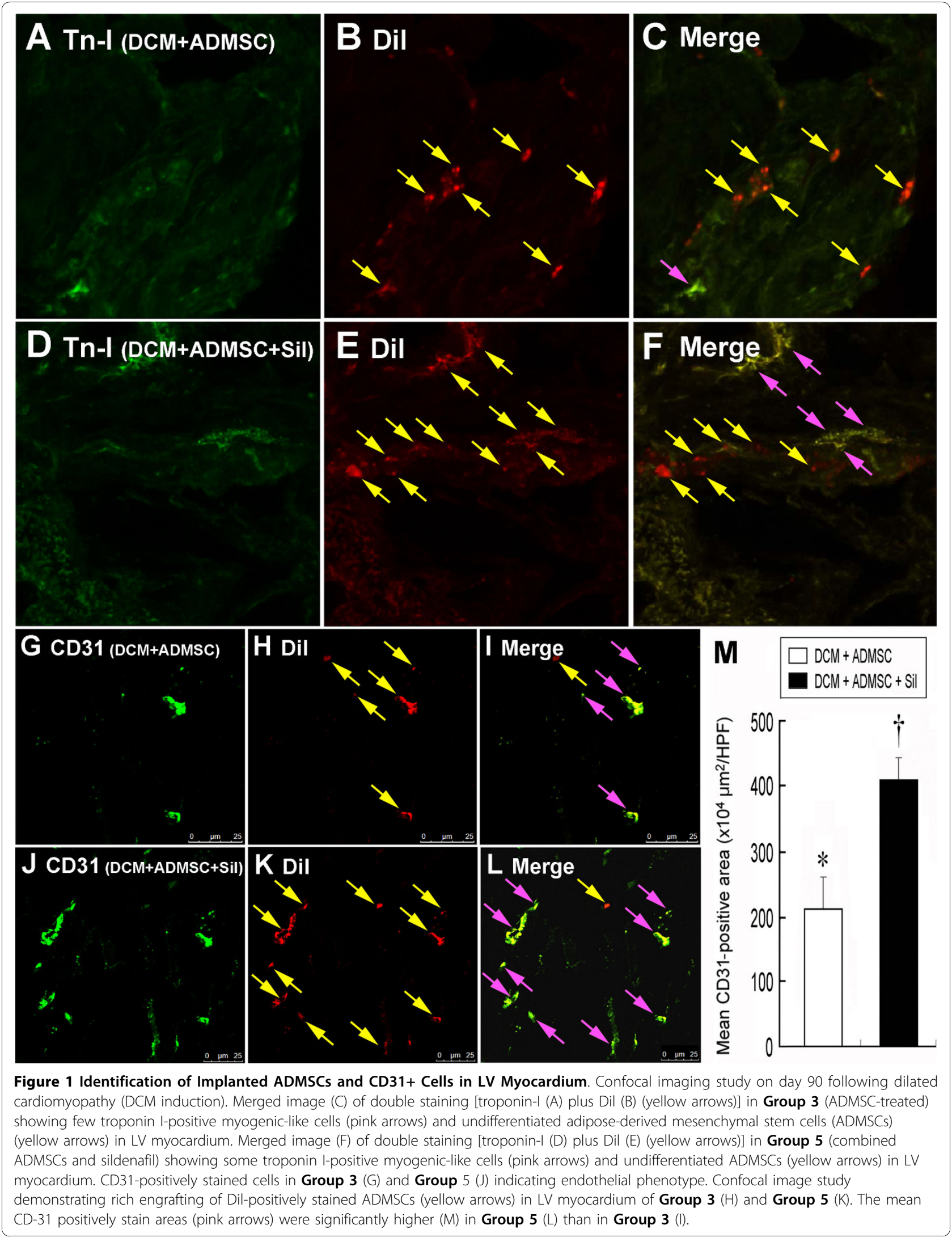




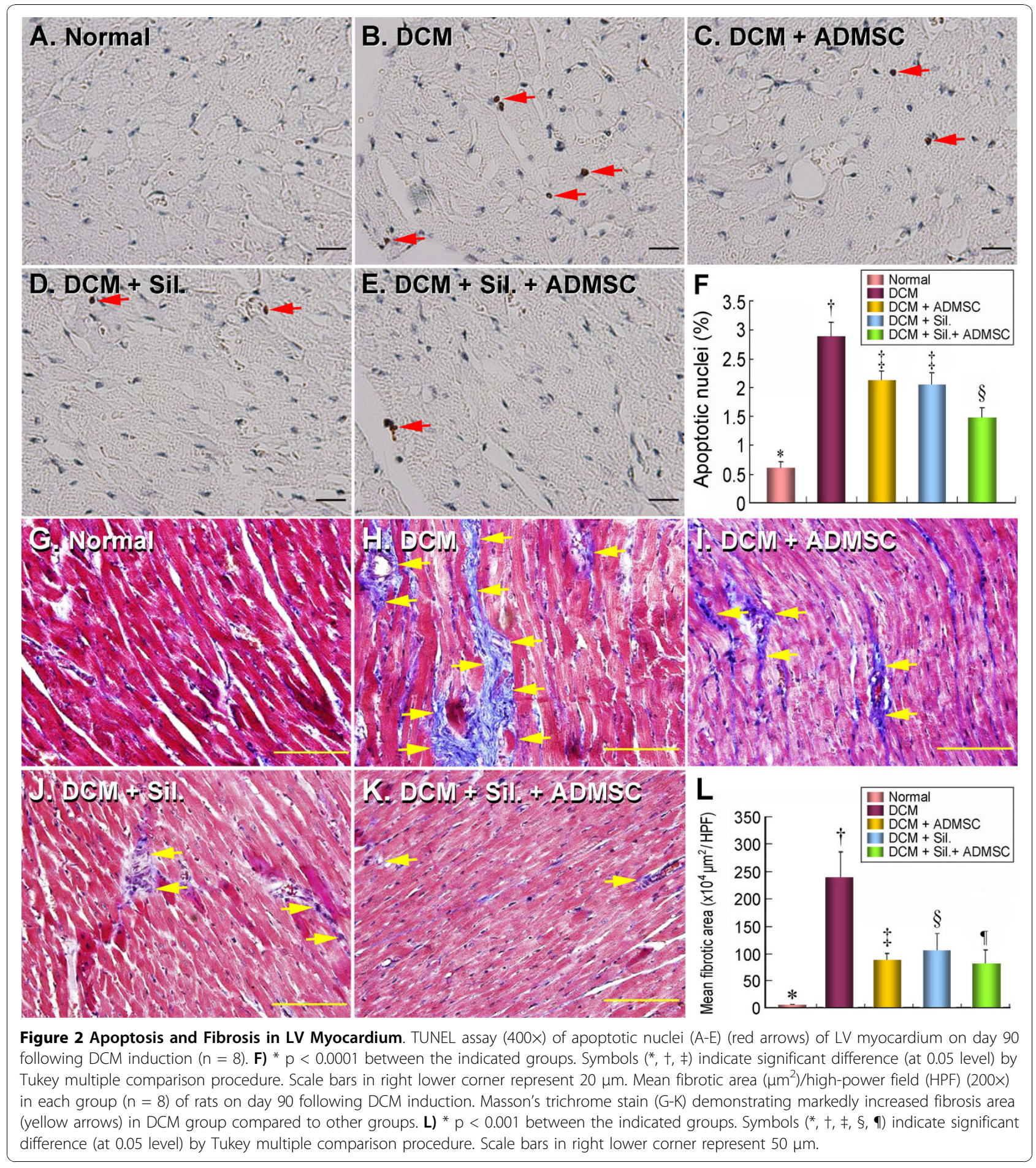

in groups 3 and 4 than group 5, and notably higher in group 5 than in group 1 (i.e. negative staining).

\section{CD40+ cell Expression in LV Myocardium and Intensity of Oxidative Stress}

To determine whether inflammatory cells were up-regulated in LV myocardium on day 90 following DCM induction, immunohistochemical staining for detection of CD40-positively stained cells was performed (Figure 3A-F). Density of CD40-positively stained cells in LV myocardium were significantly higher in group 2 than in other groups, significantly higher in groups 3 and 4 than in groups 1 and 5 , and also notably higher in group 5 than in group 1. 
The oxidative stress in mitochondria did not differ between groups 1 and 5, groups 3 and 4, and groups 4 and 5 on day 90 following DCM induction (Figure 3G). However, a significantly higher mitochondrial oxidative stress was noted in group 2 than in other groups, and in groups 3 and 4 than in group 1 . The oxidative stress was also notably higher in group 3 than in group 5 .

\section{Protein Expressions of Cytochrome C and Cx43 in LV}

Western blotting for $\mathrm{Cx} 43$ in $\mathrm{LV}$ demonstrated that $\mathrm{Cx} 43$ protein expression was similar between groups 1 and 5 and between groups 3 and 4 (Figure 4A). However, this protein expression was substantially lower in group 2 than in other groups and notably lower in groups 3 and 4 than in groups 1 and 5 (Figure 4A).

The total amount of cytochrome $\mathrm{C}$ protein expression in mitochondria was similar among groups 3 and 4 , and was also similar between group 1 and group 5 (Figure 4B). However, this protein expression in mitochondria was significantly lower in group 2 than in other groups, was also notably lower in groups 3 and 4 than in groups 1 and 5 . The total cytochrome $\mathrm{C}$ protein expression in

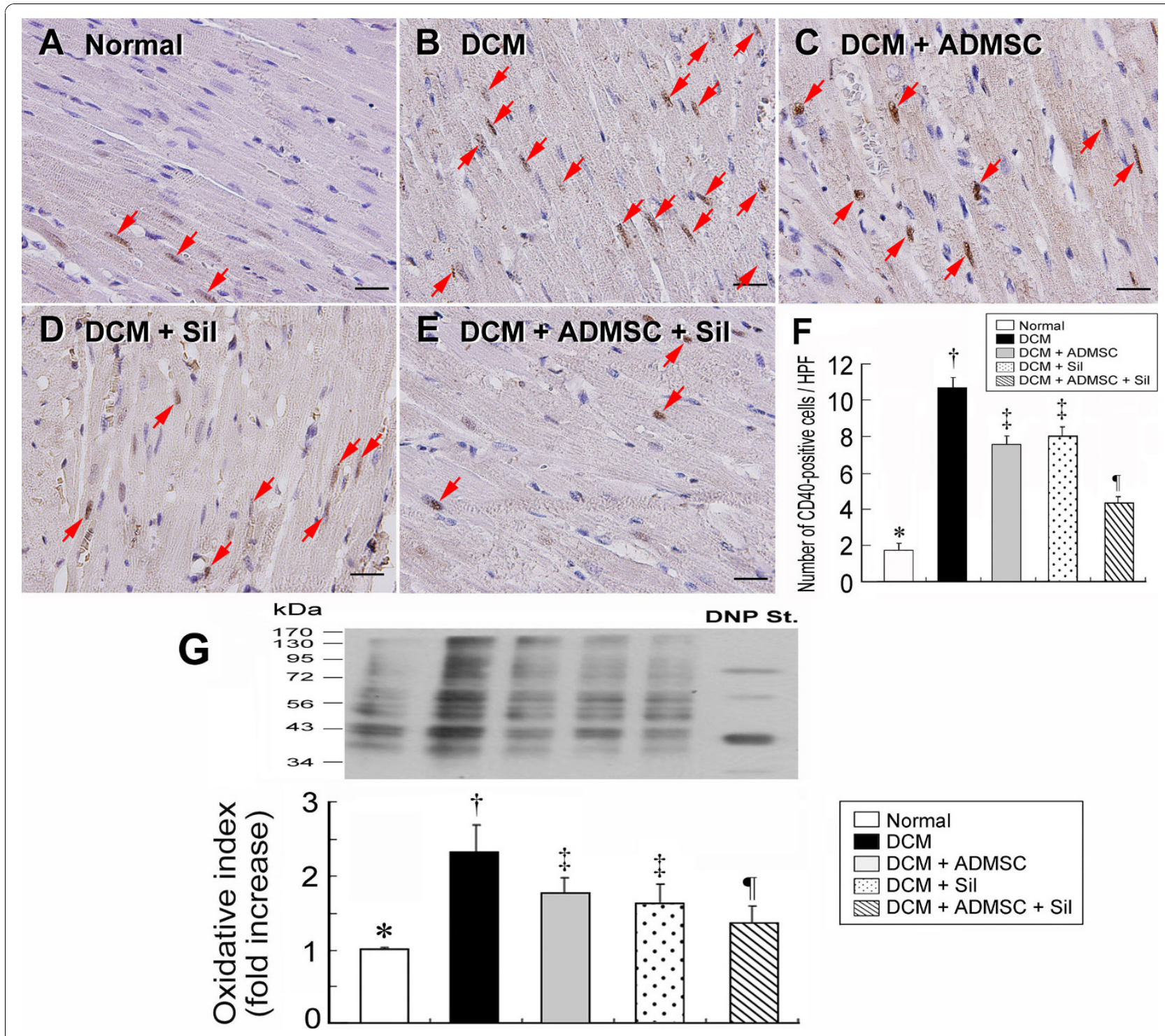

Figure 3 CD40+ Cell Expression in LV Myocardium and Intensity of Oxidative Stress. Immunohistochemical staining (400X) (A-E) for identifying CD40-positive cells (red arrows) in LV myocardium on day 90 following DCM induction ( $n=8$ in each group). F) $* p<0.0001$ between the indicated groups. Symbols $(*,+, \neq, \mathbf{9})$ indicate significant difference (at 0.05 level) by Tukey multiple comparison procedure. Scale bars in right lower corner represent $20 \mu \mathrm{m}$. Western blotting results (G) of oxidative index, protein carbonyls, in LV myocardium on day 90 following DCM induction (upper panel), with quantification results of each group $(n=8)$ (lower panel). * $p<0.0003$ between the indicated groups. Symbols $(*,+\neq, \boldsymbol{9})$ indicate significant difference (at 0.05 level) by Tukey multiple comparison procedure. Note: Right lane and left lane shown on upper panel represent control oxidized molecular protein standard and protein molecular weight marker, respectively. 


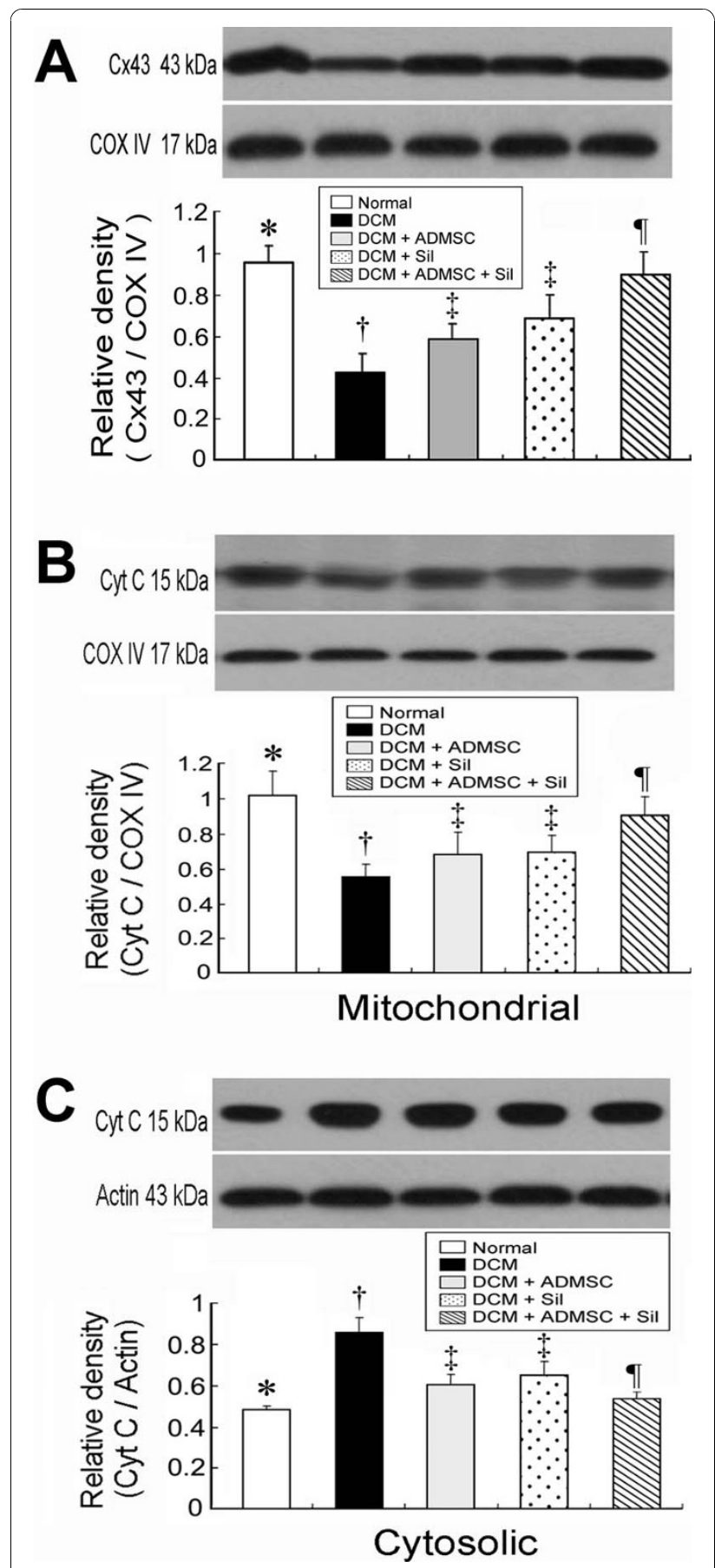

Figure 4 Protein Expressions of Cytochrome $C$ and Cx43 in LV Myocardium. (A) Connexin43 protein expression of LV myocardium on day 90 after DCM induction. ${ }^{*} p<0.0007$ between the indicated groups. B) Cytochrome $C$ protein expression in mitochondria of LV myocardium on day 90 after DCM induction. ${ }^{*} p<0.009$ between the indicated groups. C) Cytochrome $C$ protein expression in cytosol of LV myocardium on day 90 after DCM induction. ${ }^{*} p<$ 0.002 between the indicated groups. All symbols $\left({ }^{*}, \dagger_{,} \neq, \mathbf{9}\right)$ in $\left.\left.\mathbf{A}\right), \mathbf{B}\right)$ and $\mathbf{C}$ ) indicate significant difference (at 0.05 level) by Tukey multiple comparison procedure ( $n=8$ in each group) cytosol did not differ between groups 1 and 5 , as well as between groups 3 and 4 (Figure 4C). However, this cytosolic protein expression was significantly higher in group 2 than in other groups, and notably higher in groups 3 and 4 than in groups 1 and 5 . These findings indicate that the expression of cytochrome $\mathrm{C}$, an index of energy supply and storage in mitochondria, was notably lower in group 2 than in groups 1 and 5 . The increase in cytosolic cytochrome $\mathrm{C}$ content also suggested significant mitochondrial damage with cytochrome $\mathrm{C}$ release into the cytosol in the myocardium of group 2 animals.

\section{RT-PCR of LV Myocardium on Day 90 Following DCM Induction}

The mRNA expression of matrix metalloproteinase-9 mRNA, an indicator of inflammation, was markedly higher in group 2 than in other groups, notably higher in groups 3 and 4 than in groups 1 and 5 (Figure 5A). Conversely, interleukin (IL)-10 mRNA expression, an index of anti-inflammation, was significantly lower in group 2 than in other groups, notably lower in groups 3 and 4 than in groups 1 and 5 , and significantly lower in group 5 than in group 1 (Figure 5B). Additionally, eNOS mRNA expression, an index of anti-inflammation and endothelial function, was notably lower in group 2 than in other groups, significantly lower groups 3 and 4 than in group 1 (Figure $5 \mathrm{C}$ ). On the other hand, this mRNA expression was similar between group 1 and group 5, and was also similar among groups 3,4 , and 5 .

The mRNA expressions of caspase 3 (Figure 5D) and Bax (Figure 5E), indexes of apoptosis, were remarkably higher in group 2 than in other groups, markedly higher in groups 3, 4, and 5 than in group 1, and also notably lower in groups 3 and 4 than in group 5. In contrast, mRNA expression of Bcl-2, an index of anti-apoptosis, was significantly lower in group 2 than in other groups, significantly lower in groups 3 and 4 than in than in groups 1 and 5 , and also significantly lower in group 5 than in group 1 (Figure 5F). The IL-8/Gro mRNA expression, an essential chemokine guiding stem cell homing from bone marrow to damaged myocardium [23], was notably lower in groups 1 and 2 than in other groups, significantly lower in groups 3 and 4 than in group 5 (Figure 5G). Conversely, the stromal cellderived factor (SDF) $-1 \alpha$ mRNA expression, an index of endothelial progenitor cell chemokine attractant, was markedly increased in group 2 than in other groups, notably increased in groups 3 and 4 than in groups 1 and 5 (Figure $5 \mathrm{H}$ ).

The peroxisome proliferator activated receptor- $\gamma$ coactivator (PGC)-1 $\alpha$ mRNA expression, an energy transcription marker, did not differ between groups 1 and 5, or among groups 3,4 , and 5 . On the other hand, the 
mRNA expression was notably lower in group 2 than in other groups, and significantly lower in groups 3 and 4 than in group 1 (Figure 5I).

Protein Level of eNOS, SDF-1 $\alpha$, Caspase 3 and Bcl-2 of LV Myocardium on Day 90 Following DCM Induction

Western blot was performed to determine whether the initially elicited mRNA expressions of eNOS, SDF- $1 \alpha$, caspase 3 and $\mathrm{Bcl}-2$ participated in translation (Figure 6). The finings showed consistent changes in protein production compared with mRNA expressions.

\section{Small Arteriolar Density Analysis and Cardiac Hypotrophic Gene Expression}

The number of small arterioles (Figure 7A-F) $(\leq 25 \mu \mathrm{m}$ in diameter) in LV myocardium was remarkably lower in group 2 than in other groups. Moreover, the number of small arterioles was notably lower in group 1 than in groups 3,4 , and 5, significantly lower in group 4 than in groups 3 and 5, and also notably lower in group 3 than in group 5. This finding indicates that early combined treatment with sildenafil and ADMSCs is better than ADMSCs or sildenafil alone in inducing angiogenesis/vasculogenesis.

Cardiac hypertrophy is characterized by a switch of mRNA expression from $\alpha$ - to $\beta$-myosin heavy chain (MHC) (i.e. reactivation of fetal gene program) [24]. In the present study, the mRNA expression of $\beta-\mathrm{MCH}$ was significantly higher in group 2 than in other groups, notably higher in groups 3, 4, and 5 than in group 1, and also significantly higher in groups 3 and 4 than in group 5 (Figure $7 \mathrm{H}$ ). No significant difference was noted, however, between group 3 and group 4 . On the other hand, $\alpha-\mathrm{MHC}$ in LV was expressed in a reversed manner in these groups (Figure 7G).

\section{Discussion}

Effect of Combined Therapy with ADMSCs and Sildenafil on Early DCM

Our recent study demonstrated an increase in heart weight and LV remodeling in the rat DCM model [13].

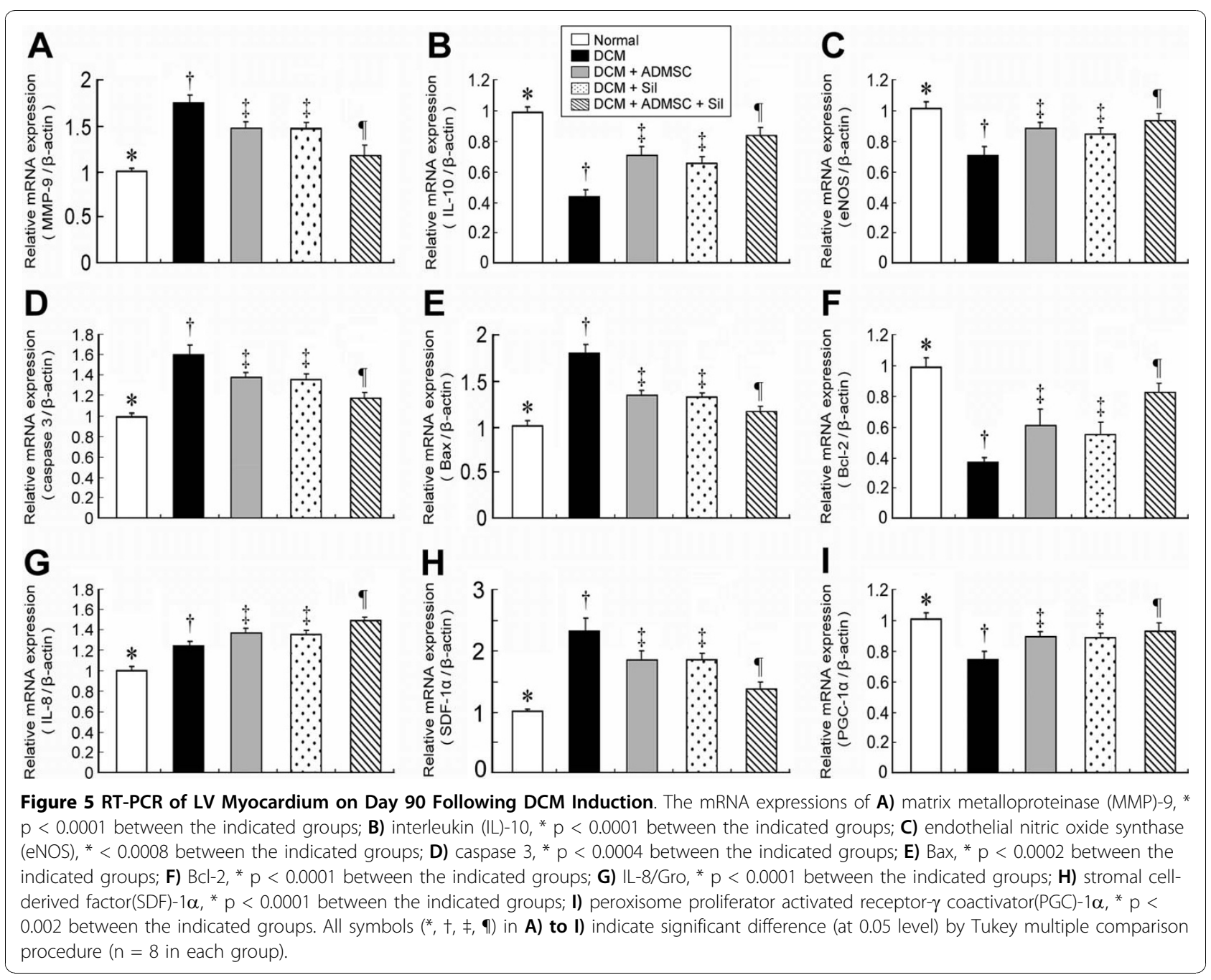


One interesting finding in the present study is that the left lung weight was notably higher in group 2 than in other groups on day 90 after DCM induction. This finding may implicate that an increase in left lung weight in DCM rat resulted in a sequestration of transudate due to CHF. Additionally, the heart weight was notably increased in group 2 than in groups 3 and 4, and it was remarkably increased as compared with group 5. Furthermore, RT-PCR showed substantially higher expression of the $\beta-M H C$ gene in LV in group 2 than in other groups, whereas an opposite trend was noted in $\alpha$-MHC gene expression in group 2 compared to other groups. Moreover, the arterial blood pressure did not differ among the five groups. These findings, in addition to supporting the reproducibility of results using our DCM model [13], further indicate that either sildenafil or ADMSC therapy offered similar effect on attenuating the progression of the hypertrophic changes in DCM that were not due to the alternation in the blood pressure. Of importance is the fact that combined therapy with ADMSCs and sildenafil is superior to either therapy alone in abrogating the progression of DCM.

\section{Lack of Evidence Supporting Differentiation of ADMSCs into the Myogenic-Like Cells for Preserving Heart Function}

Serial echocardiographic measurements in the current study showed that LV function was significantly preserved in the DCM animals with ADMSC therapy compared with that in the DCM group without treatment on day 90 after DCM induction. Recently, we have demonstrated that bone marrow-derived mononuclear cell therapy alleviated left ventricular remodeling and improved heart function in rat DCM [13]. Accordingly, the results of our present study reinforce the findings of our recent report [13]. Interestingly, flow cytometric analysis in the present study showed only a few cells that were positively stained for troponin-I prior to or on day 14 of cell culturing. Additionally, confocal image study identified that only a few implanted ADMSCs actually differentiated into troponin-I positively stained cells in LV myocardium, a phenotype of myogenic-like cells. In contrast, a fairly large number of engrafted ADMSCs were found to exhibit the undifferentiated phenotype in LV myocardium on confocal microscopic examination on day 90 following DCM induction. These findings raise the suspicion that the number of myogenic-like cells in the LV myocardium differentiated from ADMSCs is insufficient for sustaining cardiac function. Other confounding factors, therefore, may contribute to the preservation of heart function in DCM after cellular therapy.

\section{Synergic Action of Early Combined Therapy with Sildenafil and ADMSCs in Preservation of LV Function in Rat DCM}

Interestingly, while the effect of sildenafil on improving outcome of pulmonary arterial hypertension through enhanced vasodilatatory effect of cGMP $[18,19]$ has been extensively investigated in both clinical trials [25] and experimental studies [23,26,27], data regarding the impact of sildenafil on improving clinical outcome of patients with DCM has been seldom reported [20]. Thus, the role of sildenafil in the DCM setting is currently unclear. An important finding in the current study was that sildenafil therapy offered similar effect compared with ADMSC therapy on preservation of heart function in DCM rats. Accordingly, our finding strengthens the finding of previous study [20]. Another important finding in the current study is that combined therapy with ADMSCs and sildenafil more significantly preserved rat LV function than either ADMSCs or sildenafil alone on days 30 and 90 after DCM induction. These findings, therefore, highlight a potential role of this combined therapy in translational clinical application in patients with DCM.

\section{Possible Mechanisms Underlining Improvements of Heart Function in Setting of DCM Following Cellular and Sildenafil Therapy}

Recently, studies have demonstrated that angiogenesis/ vasculogenesis play an essential role in improving ischemia-related LV dysfunction [10-13,25,28]. In the present study, we found that the number of small vessels and CD31-positively stained cells, an surface marker of endothelial cells, in LV myocardium were remarkably higher in DCM rats treated with ADMSCs or sildenafil than in those DCM animals without treatment, whereas it was significantly higher in the combined therapy group than in other groups. Moreover, eNOS gene and protein expressions, an index of endothelial function and angiogenesis [22], were found to show a similar increase comparable to the number of small vessels and CD31-positively stained cells in LV myocardium of each group. Interestingly, previous experimental study has demonstrated that sildenafil enhanced eNOS mRNA expression [22]. Our findings, in addition to corroborating the results of recent studies [10-13,23,25,28], may at least in part explain the mechanisms underlying sildenafil and cell therapy in preserving LV function in the rodent DCM model. Besides, our results also revealed the difference in therapeutic benefits offered by the three regimens in our experiment setting.

Growing data suggest that cytokine effect $[12,13,28]$ is another important mechanism underlying the restoration of ischemia-related LV dysfunction. Both SDF-1 $\alpha$ 


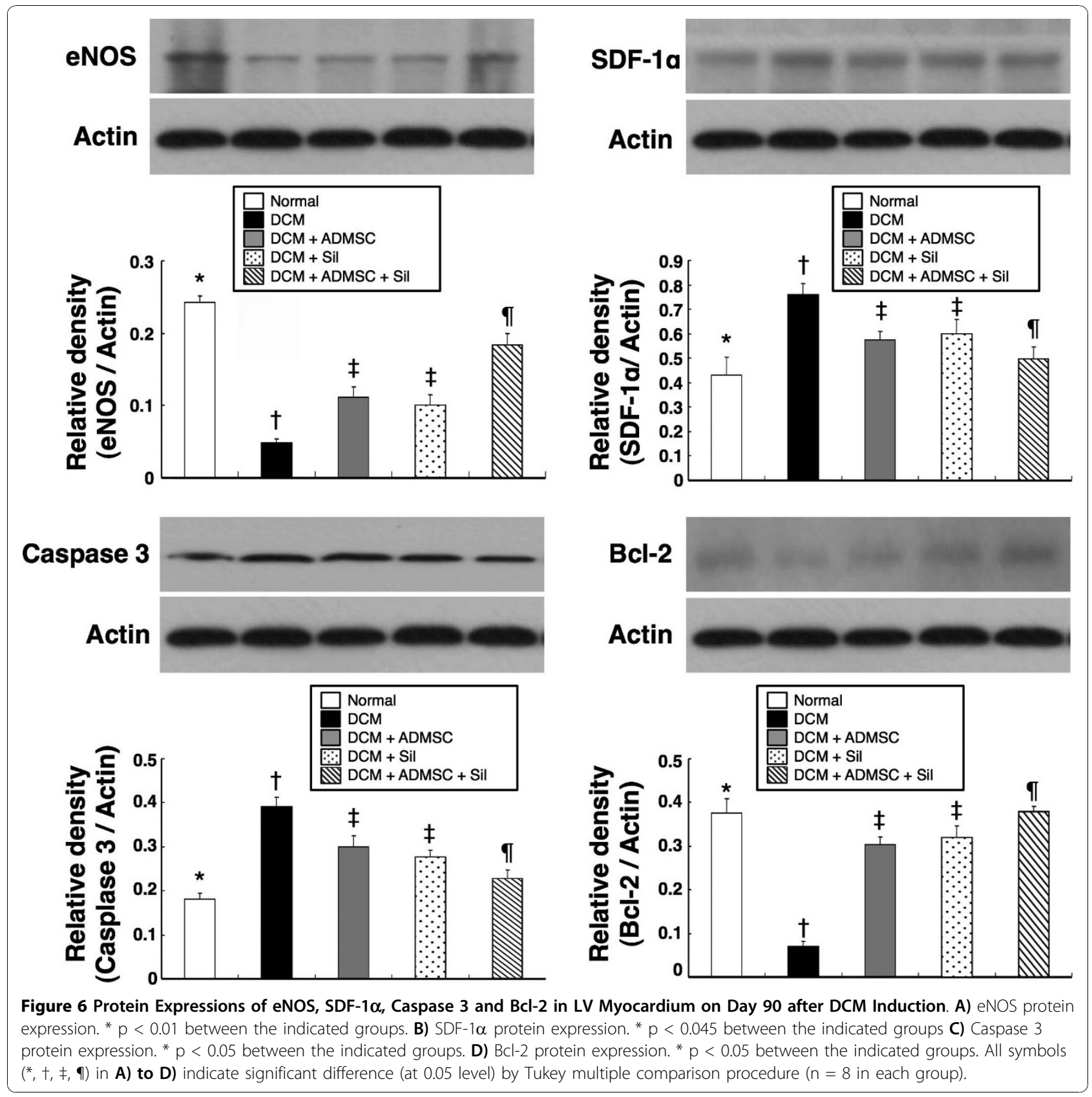

and IL-8/Gro CXC chemokines have been found to be crucial in the mobilization, incorporation, homing, survival, proliferation, and differentiation of stem cells $[29,30]$. In the current study, IL-8/Gro mRNA expression was found to be notably higher in animals receiving either ADMSC or sildenafil therapy and remarkably increased in the combined treatment group as compared with DCM alone. Our finding was comparable to those of previous studies $[29,30]$. Interestingly, mRNA and protein expressions of SDF-1 $\alpha$ were found to show a negative correlation with that of IL-8/Gro in the animals. This finding may suggest that higher level of SDF-1 may be secreted by the ischemic tissue in response to the severity of ischemia to attract the endothelial progenitor cells for tissue repair.

The link between an increase of inflammation/reactive oxygen species (ROS) and apoptosis/cellular death in ischemic myocardium has been established [12,13,31-33]. Accordingly, our results demonstrated remarkably increased gene and protein expressions of MMP-9, the number of CD40-positively stained cells, and oxidative stress in group 2 compared with other groups. These 


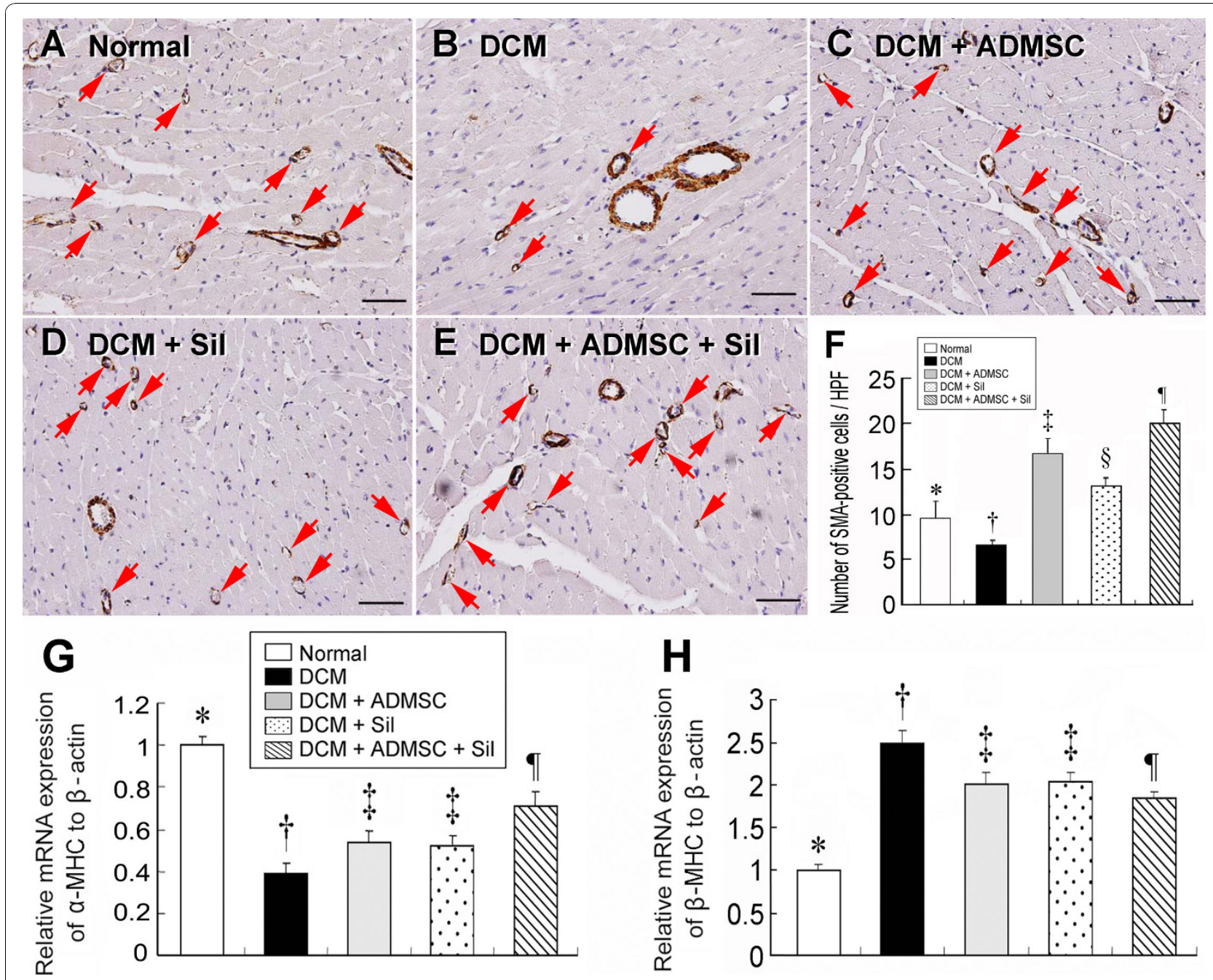

Figure 7 Small Arteriolar Density Analysis and Cardiac Hypotrophic Gene Expression. $\alpha$-SMA immunohistochemical staining (A-E) (200X) for the number of small arterioles ( $\leq 25 \mu \mathrm{m}$ in diameter) in LV myocardium on day 90 after DCM induction. The results showing notably lower small vessel (red arrows) number in DCM group than in other groups. $\mathbf{F}$ ) ${ }^{*} p<0.0001$ between the indicated groups. Scale bars in right lower corner represent $50 \mu \mathrm{m}(n=8$ in each group). The mRNA expressions of $\alpha$-myosin heavy chain (MHC) (G) and $\beta$-MHC of LV myocardium on day 90 after DCM induction. G) ${ }^{*} p<0.003$ between the indicated groups. $\left.\mathbf{H}\right) * p<0.0003$ between the indicated groups. All symbols $\left.{ }^{*},+, \neq, \S, \mathbf{q}\right)$ in F), G) and $\mathbf{H}$ ) indicate significant difference (at 0.05 level) by Tukey multiple comparison procedure ( $n=8$ in each group).

parameters were also notably elevated in groups 3 and 4 than in group 5. In contrast, mRNA expressions of IL-10 and eNOS, the anti-inflammatory indicators, were lowest in group 2 and significantly decreased in groups 3 and 4 compared to that in group 5. Furthermore, the apoptotic biomarkers of apoptotic nuclei and Bax as well as mRNA and protein expressions of caspase 3 were notably higher, whereas both mRNA and protein expressions of Bcl-2, an anti-apoptosis biomarker, was remarkably lowest in group 2 . Stem cell therapy has been proposed to be immune-modulatory and anti-inflammatory through down-regulating both innate and adaptive immunity [13,34]. Additionally, sildenafil has been found to possess anti-inflammatory, anti-fibroproliferative, and anti-apoptotic properties [23]. Our findings not only strengthen the hypothesis $[13,23]$ and the findings of previous report [34], but also provide insight into the mechanisms underlying the reduction in fibrosis and cellular apoptosis of LV myocardium in rodent DCM after ADMSC treatment. Besides, our findings further supports that combined therapy with ADMSCs and sildenafil provide an additional benefit compared to either ADMSC or sildenafil therapy alone in significantly limiting DCM-related cardiac dysfunction.

The principal finding in the current study is that RTPCR showed a markedly lower mRNA expressions of PGC-1 $\alpha$ which is a transcriptional coactivator of oxidative 
metabolism, mitochondrial metabolism and biogenesis $[13,35,36]$ in group 2 than in other groups, and lower in groups 3 and 4 than in group 5. Moreover, Western blot analysis identified a significantly lower mitochondrial cytochrome $\mathrm{C}$ content in group 2 compared with that in other groups. It was also notably lower in groups 3 and 4 than in group 5, whereas its cytosolic counterpart showed respectively opposite changes in the study groups. These findings suggest a significant preservation of mitochondrial integrity and functions from combined treatment. Furthermore, changes in $\mathrm{Cx} 43$ expression pattern have been reported to be associated with various cardiac pathologies and contribute to the development of cardiac arrhythmia [37]. The reduction in Cx43 protein expression in a DCM setting implies a perturbation in cell-to-cell interconnections [13] and hence electrical coupling and cellular signal transductions [37]. Of importance in the present study is that combined therapy with ADMSCs and sildenafil was better than either therapeutic option alone in preventing the down-regulation of $\mathrm{Cx} 43$ expression in the rodent DCM model. Therefore, not only may the current study provide explanations for the improved cardiac function after combined therapy with ADMSCs and sildenafil in the DCM animals, it also further strengthens the findings from previous studies [13,35-37].

\section{Study Limitation}

This study has limitations. First, although sildenafil has been clearly shown to cause vasodilatation through an increase of cGMP concentration in smooth muscle $[17,18]$, the mechanisms through which sildenafil enhanced ADMSCs' participation in the process of myocardial regeneration has not been investigated in this study. The precise role of cGMP-dependent signaling in the setting of DCM, therefore, remains unclear. Second, except for LVEF and arterial blood pressure, other physiological parameters for monitoring LV remodeling including pressure-volume loop, left ventricular end-diastolic pressure, and pulmonary vascular resistance were not provided in the current study.

In conclusion, our results demonstrated that early combined treatment with ADMSCs and sildenafil for DCM rats not only is superior to either ADMSC or sildenafil alone through eliciting serial molecular-cellular biological effects in the preservation of LV function. These findings may raise the need for further

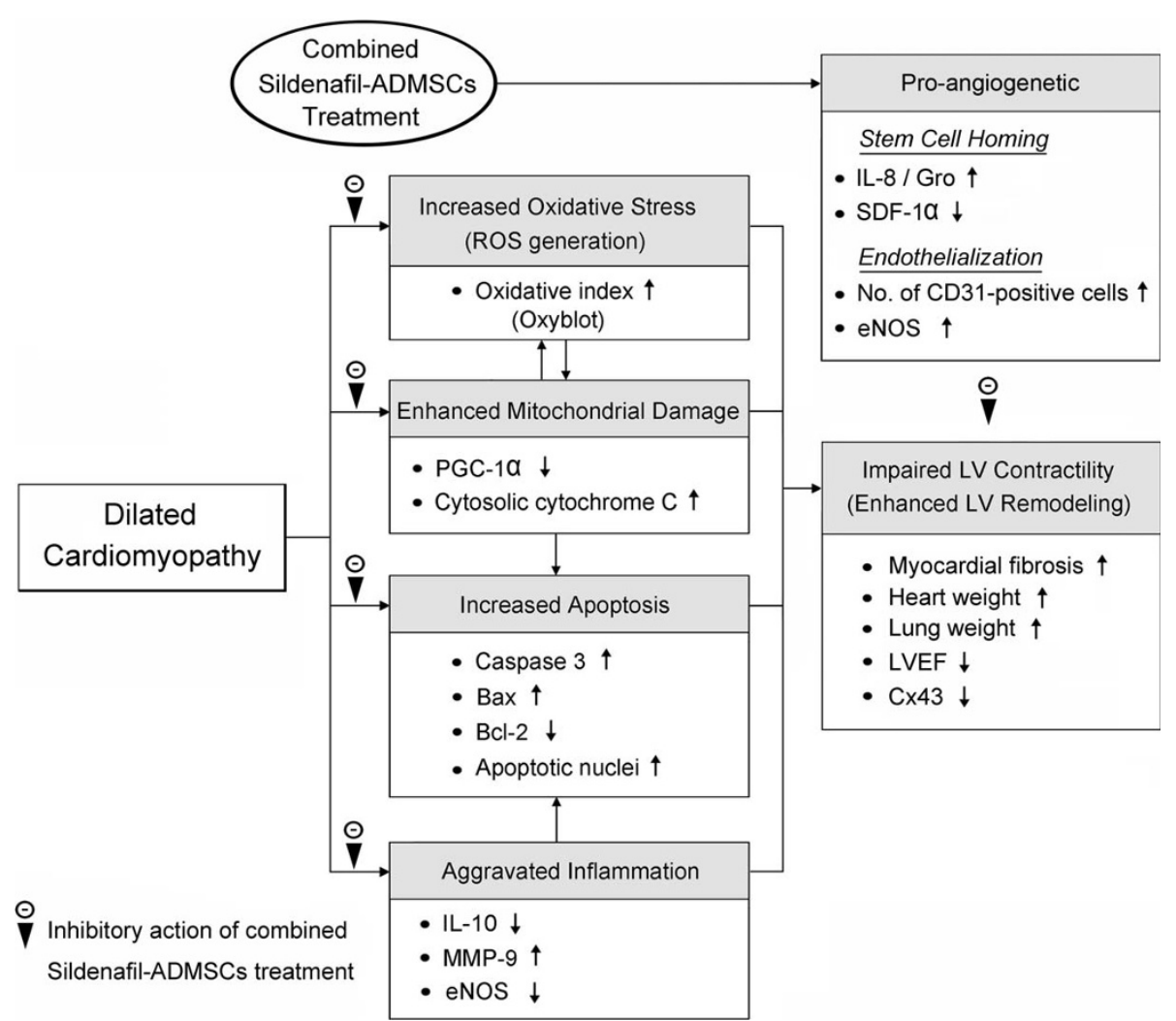

Figure 8 The Proposed Mechanisms. ADMSCs: Adipose-derived mesenchymal stem cells; ROS: Reactive oxygen species; PGC-1 $\alpha$ : Peroxisome proliferator activated receptor- $\gamma$ coactivator-1 $\alpha$; MMP-9: Matrix metalloproteinase-9; eNOS: Endothelial nitric oxide synthase; SDF-1 $\alpha$ : Stromal cellderived factor-1 $\alpha$; LVEF: Left ventricular ejection fraction; Cx43: Connexin 43 
prospective studies on assessing the therapeutic potential of combined ADMESC-sildenafil regimen in human subjects with DCM. The proposed mechanisms underlying the potential impacts of combined ADMSC-sildenafil therapy against DCM rats have been summarized in Figure 8 .

\section{Acknowledgements}

This study is supported by a program grant from Chang Gung Memorial Hospital, Chang Gung University (grant no. CMRPG 881241).

\section{Author details \\ 'Division of cardiology, Department of Internal Medicine, Chang Gung Memorial Hospital-Kaohsiung Medical Center, Chang Gung University College of Medicine, Kaohsiung, Taiwan. ${ }^{2}$ Center for Translational Research in Biomedical Sciences, Chang Gung Memorial Hospital-Kaohsiung Medical Center, Chang Gung University College of Medicine, Kaohsiung, Taiwan. ${ }^{3}$ Division of General Surgery, Department of Surgery, Chang Gung Memorial Hospital-Kaohsiung Medical Center, Chang Gung University College of Medicine, Kaohsiung, Taiwan. ${ }^{4}$ Department of Life Science, National Pingtung University of Science and Technology, Pingtung, Taiwan. ${ }^{5}$ Department of Medical Research, E-DA Hospital, I-Shou University, Kaohsiung, Taiwan. ${ }^{6}$ Basic Science, Nursing Department, Meiho University, Pingtung, Taiwan. ${ }^{7}$ Department of Radiology, Chang Gung Memorial Hospital-Kaohsiung Medical Center, Chang Gung University College of Medicine, Kaohsiung, Taiwan. ${ }^{8}$ Division of Cardiovascular Surgery, Department of Surgery, Chang Gung Memorial Hospital-Kaohsiung Medical Center, Chang Gung University College of Medicine, Kaohsiung, Taiwan.}

\section{Authors' contributions}

All authors have read and approved the final manuscript. Dr. Fan-Yen Lee contributed equally to this work compared with the corresponding author. $Y C L, C K S$, and SL designed the experiment, drafted the manuscript, and performed animal experiments. LTC, CHY, THT, SC, MF, SFK, CJW, and YHK were responsible for the laboratory assay and troubleshooting. FYL and HKY participated in refinement of experiment protocol and coordination and helped in drafting the manuscript.

\section{Competing interests}

The authors declare that they have no competing interests.

Received: 21 June 2010 Accepted: 26 September 2010 Published: 26 September 2010

\section{References}

1. Garg R, Yusuf S: Overview of randomized trials of angiotensin-converting enzyme inhibitors on mortality and morbidity in patients with heart failure. Collaborative Group on ACE Inhibitor Trials. Jama 1995, 273:1450-1456.

2. Pitt B, Poole-Wilson PA, Segal R, Martinez FA, Dickstein K, Camm AJ, Konstam MA, Riegger G, Klinger GH, Neaton J, et al: Effect of losartan compared with captopril on mortality in patients with symptomatic heart failure: randomised trial-the Losartan Heart Failure Survival Study ELITE II. Lancet 2000, 355:1582-1587.

3. Solomon SD, Wang D, Finn P, Skali H, Zornoff L, McMurray JJ, Swedberg K, Yusuf S, Granger CB, Michelson EL, et al: Effect of candesartan on causespecific mortality in heart failure patients: the Candesartan in Heart failure Assessment of Reduction in Mortality and morbidity (CHARM) program. Circulation 2004, 110:2180-2183.

4. Frazier $\mathrm{OH}$, Benedict $\mathrm{CR}$, Radovancevic B, Bick RJ, Capek P, Springer WE, Macris MP, Delgado R, Buja LM: Improved left ventricular function after chronic left ventricular unloading. Ann Thorac Surg 1996, 62:675-681, discussion 681-672.

5. Dandel $M$, Weng $Y$, Siniawski H, Potapov E, Lehmkuhl HB, Hetzer R: Longterm results in patients with idiopathic dilated cardiomyopathy after weaning from left ventricular assist devices. Circulation 2005, 112:137-45.

6. Poole-Wilson PA, Swedberg K, Cleland JG, Di Lenarda A, Hanrath P, Komajda M, Lubsen J, Lutiger B, Metra M, Remme WJ, et al: Comparison of carvedilol and metoprolol on clinical outcomes in patients with chronic heart failure in the Carvedilol Or Metoprolol European Trial (COMET): randomised controlled trial. Lancet 2003, 362:7-13.

7. Di Lenarda A, Remme WJ, Charlesworth A, Cleland JG, Lutiger B, Metra M, Komajda M, Torp-Pedersen C, Scherhag A, Swedberg K, Poole-Wilson PA: Exchange of beta-blockers in heart failure patients. Experiences from the poststudy phase of COMET (the Carvedilol or Metoprolol European Trial). Eur J Heart Fail 2005, 7:640-649.

8. Tomita S, Li RK, Weisel RD, Mickle DA, Kim EJ, Sakai T, Jia ZQ: Autologous transplantation of bone marrow cells improves damaged heart function. Circulation 1999, 100:11247-256.

9. Strauer BE, Brehm M, Zeus T, Kostering M, Hernandez A, Sorg RV, Kogler G, Wernet P: Repair of infarcted myocardium by autologous intracoronary mononuclear bone marrow cell transplantation in humans. Circulation 2002, 106:1913-1918.

10. Davani S, Marandin A, Mersin N, Royer B, Kantelip B, Herve P, Etievent JP, Kantelip JP: Mesenchymal progenitor cells differentiate into an endothelial phenotype, enhance vascular density, and improve heart function in a rat cellular cardiomyoplasty model. Circulation 2003, 108(Suppl 1):|1253-258.

11. Dai W, Hale SL, Martin BJ, Kuang JQ, Dow JS, Wold LE, Kloner RA: Allogeneic mesenchymal stem cell transplantation in postinfarcted rat myocardium: short-and long-term effects. Circulation 2005, 112:214-223.

12. Yip HK, Chang LT, Wu CJ, Sheu JJ, Youssef AA, Pei SN, Lee FY, Sun CK: Autologous bone marrow-derived mononuclear cell therapy prevents the damage of viable myocardium and improves rat heart function following acute anterior myocardial infarction. Circ J 2008, 72:1336-1345.

13. Sun CK, Chang LT, Sheu JJ, Chiang CH, Lee FY, Wu CJ, Chua S, Fu M, Yip HK: Bone marrow-derived mononuclear cell therapy alleviates left ventricular remodeling and improves heart function in rat-dilated cardiomyopathy. Crit Care Med 2009, 37:1197-1205.

14. Boolell M, Allen MJ, Ballard SA, Gepi-Attee S, Muirhead GJ, Naylor AM,

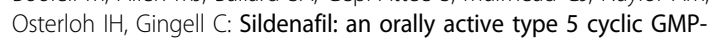
specific phosphodiesterase inhibitor for the treatment of penile erectile dysfunction. Int J Impot Res 1996, 8:47-52.

15. Goldenberg MM: Safety and efficacy of sildenafil citrate in the treatment of male erectile dysfunction. Clin Ther 1998, 20:1033-1048.

16. Ahn HS, Foster M, Cable M, Pitts BJ, Sybertz EJ: Ca/CaM-stimulated and CGMP-specific phosphodiesterases in vascular and non-vascular tissues. Adv Exp Med Biol 1991, 308:191-197.

17. Zhao L, Mason NA, Morrell NW, Kojonazarov B, Sadykov A, Maripov A, Mirrakhimov MM, Aldashev A, Wilkins MR: Sildenafil inhibits hypoxiainduced pulmonary hypertension. Circulation 2001, 104:424-428.

18. Shekerdemian LS, Ravn HB, Penny DJ: Intravenous sildenafil lowers pulmonary vascular resistance in a model of neonatal pulmonary hypertension. Am J Respir Crit Care Med 2002, 165:1098-1102.

19. Banas A, Teratani T, Yamamoto Y, Tokuhara M, Takeshita F, Osaki M, Kawamata M, Kato T, Okochi H, Ochiya T: IFATS collection: in vivo therapeutic potential of human adipose tissue mesenchymal stem cells after transplantation into mice with liver injury. Stem Cells 2008, 26:2705-2712.

20. Behling A, Rohde LE, Colombo FC, Goldraich LA, Stein R, Clausell N: Effects of $5^{\prime}$-phosphodiesterase four-week long inhibition with sildenafil in patients with chronic heart failure: a double-blind, placebo-controlled clinical trial. J Card Fail 2008, 14:189-197.

21. Muranaka H, Marui A, Tsukashita M, Wang J, Nakano J, Ikeda T, Sakata R: Prolonged mechanical unloading preserves myocardial contractility but impairs relaxation in rat heart of dilated cardiomyopathy accompanied by myocardial stiffness and apoptosis. J Thorac Cardiovasc Surg 2010.

22. Yen CH, Leu S, Lin YC, Kao YH, Chang LT, Chua S, Fu M, Wu CJ, Sun CK, Yip HK: Sildenafil Limits Monocrotaline-Induced Pulmonary Hypertension in Rats through Suppression of Pulmonary Vascular Remodeling. J Cardiovasc Pharmacol 2010, 55:574-584.

23. Kocher AA, Schuster MD, Bonaros N, Lietz K, Xiang G, Martens TP, Kurlansky PA, Sondermeijer H, Witkowski P, Boyle A, et al: Myocardial homing and neovascularization by human bone marrow angioblasts is regulated by IL-8/Gro CXC chemokines. J Mol Cell Cardiol 2006, 40:455-464.

24. Nagaya N, Kangawa $K$, Itoh T, Iwase T, Murakami S, Miyahara $Y$, Fujii T, Uematsu M, Ohgushi H, Yamagishi M, et al: Transplantation of 
mesenchymal stem cells improves cardiac function in a rat model of dilated cardiomyopathy. Circulation 2005, 112:1128-1135.

25. Blanco I, Gimeno E, Munoz PA, Pizarro S, Gistau C, Rodriguez-Roisin R, Roca J, Barbera JA: Hemodynamic and gas exchange effects of sildenafil in patients with chronic obstructive pulmonary disease and pulmonary hypertension. Am J Respir Crit Care Med 181:270-278.

26. Schermuly RT, Kreisselmeier KP, Ghofrani HA, Yilmaz H, Butrous G, Ermert L, Ermert M, Weissmann N, Rose F, Guenther A, et al: Chronic sildenafil treatment inhibits monocrotaline-induced pulmonary hypertension in rats. Am J Respir Crit Care Med 2004, 169:39-45.

27. Tse HF, Kwong YL, Chan JK, Lo G, Ho CL, Lau CP: Angiogenesis in ischaemic myocardium by intramyocardial autologous bone marrow mononuclear cell implantation. Lancet 2003, 361:47-49.

28. Kucia M, Reca R, Miekus K, Wanzeck J, Wojakowski W, JanowskaWieczorek A, Ratajczak J, Ratajczak MZ: Trafficking of normal stem cells and metastasis of cancer stem cells involve similar mechanisms: pivotal role of the SDF-1-CXCR4 axis. Stem Cells 2005, 23:879-894.

29. Kee HJ, Sohn IS, Nam Kl, Park JE, Qian YR, Yin Z, Ahn Y, Jeong MH, Bang YJ, Kim N, et al: Inhibition of histone deacetylation blocks cardiac hypertrophy induced by angiotensin II infusion and aortic banding. Circulation 2006, 113:51-59.

30. Frangogiannis NG, Smith CW, Entman ML: The inflammatory response in myocardial infarction. Cardiovasc Res 2002, 53:31-47.

31. Frangogiannis NG: The immune system and cardiac repair. Pharmacol Res 2008, 58:88-111.

32. Garrido AM, Griendling KK: NADPH oxidases and angiotensin II receptor signaling. Mol Cell Endocrinol 2009, 302:148-158.

33. Thum T, Bauersachs J, Poole-Wilson PA, Volk HD, Anker SD: The dying stem cell hypothesis: immune modulation as a novel mechanism for progenitor cell therapy in cardiac muscle. J Am Coll Cardiol 2005, 46:1799-1802.

34. Garnier A, Fortin D, Delomenie C, Momken I, Veksler V, Ventura-Clapier R: Depressed mitochondrial transcription factors and oxidative capacity in rat failing cardiac and skeletal muscles. J Physiol 2003, 551:491-501.

35. Suwa M, Nakano H, Kumagai S: Effects of chronic AICAR treatment on fiber composition, enzyme activity, UCP3, and PGC-1 in rat muscles. J Appl Physiol 2003, 95:960-968.

36. Kirchhoff S, Nelles E, Hagendorff A, Kruger O, Traub O, Willecke K: Reduced cardiac conduction velocity and predisposition to arrhythmias in connexin40-deficient mice. Curr Biol 1998, 8:299-302.

37. Peters NS, Green CR, Poole-Wilson PA, Severs NJ: Cardiac arrhythmogenesis and the gap junction. J Mol Cell Cardiol 1995, 27:37-44.

doi:10.1186/1479-5876-8-88

Cite this article as: Lin et al:: Early combined treatment with sildenafil and adipose-derived mesenchymal stem cells preserves heart function in rat dilated cardiomyopathy. Journal of Translational Medicine 2010 8:88. 